\section{Apropiaciones y usos de la canción criolla (1900-1939)}

\section{Emilio Bustamante}

a canción criolla es considerada - como un producto cultural de los sectores populares urbanos de comienzos del siglo XX. Se plantea que la canción criolla fue creada y empleada por dichos sectores populares para expresar sus valores y vivencias; pero que fue también usada por el Estado y la elite en función de sus necesidades hegemónicas desde la década de 1930, contando para ello con los medios de comunicación masiva, especialmente la radio.

\section{Canción criolla, cultura hegemónica y cultura popular}

Nos referimos aquí a la canción criolla como manifestación de la cultura popular urbana limeña. Abordamos su origen, fuentes, influencias y apropiaciones, el contexto en el que se desarrolló, los cambios en el modo de vida y valores de los sectores populares que representó, y sus contactos y relaciones con la cultura de elite y la cultura de masas a fines de los años treinta.

Desde nuestro punto de vista, los creadores de la canción criolla se apropian, a fines del siglo XIX y comienzos del siglo XX, de formas musicales y poéticas que han sido o son dejadas de lado por la cultura de elite, pero que todavía son útiles a los sectores populares para la representación de su vida. Esta apropiación no es muy diferente de la que hacen estos sectores de 
otros bienes o productos materiales desechados por la elite, desde la comida -recordemos que de las sobras y descartes es que nace buena parte de la llamada "comida criolla" - hasta los electrodomésticos. Tal apropiación, sin embargo, no es mecánica e implica una transformación del bien recogido a fin de satisfacer las necesidades del pueblo. En esa transformación intervienen significados y valores que forman parte de la cultura de los sectores populares urbanos. Por último, es verdad que esa apropiación ratifica la situación de subordinación de los grupos marginales, pero también facilita su expresión y supervivencia. La transformación evidencia, por su parte, la capacidad creadora y reproductiva de la cultura popular.

Hacia fines de los años treinta, en un periodo de crisis de representatividad del Estado y de la cultura de elite que se pretende hegemónica, Estado y elite otorgan a la canción criolla reconocimiento como manifestación cultural de carácter nacional, pero sometiéndola a ciertos parámetros y "depuraciones". Por su parte, los medios de comunicación, en especial la radio, la acogen y permiten su expansión, pero también con modificaciones e integrándola a otro sistema de significaciones y valores.

\section{La canción criolla: Definición y etapas}

Lloréns $^{1}$ distingue lo que llama la "música criolla" de lo que más ampliamente puede denominarse "música popular costeña". Entiende por música criolla "a la producida y consumida en Lima, constituida básicamente por dos géneros: el valse y la polca". ${ }^{2}$ Añade tibiamente a la marinera, género algo más antiguo que los mencionados, practicada inicialmente solo por la etnia negra, pero que luego de la Guerra del Pacífico es acogida en fiestas populares por negros, mestizos y blancos. Excluye de la definición a los géneros populares cuya producción y consumo se hallaba limitado a la etnia negra, "aunque fueran urbanos y limeños", tales como el amorfino, ${ }^{3}$ y también a otras manifestaciones musicales de la costa, como la marinera norteña y el tondero.

Aunque la restricción de Lloréns sea discutible, permite:

\footnotetext{
1 LLORÉNS, José Antonio. Música popular en Lima. Criollos y andinos, 1983 y "De la Guardia Vieja a la generación de Pinglo: Música criolla y cambio social en Lima 1940-1940”, en STEIN, Steve (comp.). Lima obrera 1900-1930. Tomo II, 1987.

2 LLÓRENS, José Antonio. Op. cit., 1987, p. 258.

3 Ibídem, p. 259.
} 
- Centrar la atención en ciertos géneros relativamente nuevos y de alcance amplio entre los sectores populares limeños urbanos hacia fines del siglo XIX y comienzos del siglo XX.

- Establecer un vínculo entre el proceso que siguió la canción criolla en el siglo XX con las representaciones de la cultura de elite, que identificaba a lo peruano con lo criollo, y a lo criollo con lo limeño. De acuerdo con ello, la representación que la elite criolla tenía del "pueblo" era el pueblo limeño, y no había más manifestaciones populares dignas de atención que las de ese pueblo. La música popular limeña sería pues designada como música criolla. Más tarde -obedeciendo a ciertos intereses y necesidades hegemónicas, y siguiendo la lógica que iguala a Lima con el Perú- esta música sería celebrada como "la música peruana".

Se pueden distinguir tres etapas en los primeros cincuenta años de la canción criolla. ${ }^{4}$ La primera, la de la llamada Guardia Vieja, comprendería desde fines del siglo XIX hasta 1920, aproximadamente; de ella han quedado algunas canciones y pocos nom- bres de autores. La segunda es una breve etapa de crisis y comprende el primer lustro de los años veinte, cuando se operan cambios importantes en la estructura urbana de Lima y se empieza a sentir en los barrios populares la influencia de nuevos géneros musicales, especialmente los norteamericanos (fox trot, charleston, one step) y el tango argentino. La tercera es la de la llamada generación de Pinglo, donde los autores están ya más o menos individualizados, y comprende desde 1926, aproximadamente, hasta "cerca de 1950".5 En esta última etapa la música criolla asimila las influencias extranjeras, se moderniza y renueva los temas de las canciones, que abarcan desde el fútbol hasta el automóvil, pasando por las mujeres y los niños trabajadores, los cabarés, el cine y los fumaderos de opio. Es en ella, también, cuando el género más destacado de la canción criolla, el vals, se convierte, según Steve Stein, "en la tendencia principal de la música de la clase trabajadora urbana", 6 y cuando por fin la canción criolla tiene acceso a la difusión masiva a través de la radio, especialmente a partir de 1937. La culminación de esta etapa está marcada por un hecho significativo: la creación, por parte del Estado, del Día

LLORÉNS, José Antonio. Op. cit., 1983 y 1987.

5 LLORÉNS, José Antonio. Op. cit., 1983, p. 62.

6 STEIN, Steve. "El vals criollo en los valores de la clase trabajadora en la Lima de comienzos del siglo XX”. Op. cit., tomo I, 1986, p. 89. 
de la Canción Criolla" en 1944, que marca tanto el reconocimiento de la elite gobernante a una manifestación de la cultura popular como su apropiación por esta misma elite con fines hegemónicos.

\section{Los autores}

Los músicos y compositores criollos provenían de sectores populares urbanos; eran en su mayoría artesanos y obreros. $^{7}$ Steve Stein, quien en 1971 realizó varias entrevistas a compositores y cantantes de la Guardia Vieja y la generación de Pinglo afirma que:

La estrecha identificación de la música criolla con las masas populares llevó al total rechazo de tal música por parte de las clases alta y media de Lima. La antipatía exhibida por estos últimos grupos hacia la expresión popular alcanzó tal virulencia que los músicos de clase baja a menudo sufrieron agresiones verbales $\mathrm{y}$, en ocasiones, físicas, cuando llevaban abiertamente sus guitarras en vecindarios aristocráticos. En las pocas ocasiones en que el vals criollo se deslizó fuera del callejón a un área de clase alta, los que lo tocaban o cantaban trataban a la música casi como un objeto subversivo, y se aseguraban de confinar su 'impropiedad' a los cuartos traseros de la casa para evitar ser escuchados por los vecinos. ${ }^{8}$

Stein añade que la cantante Rosita Ascoy recordó en una entrevista con él haber intentado "mantener en secreto su interés por la música criolla ante su madre de clase media". 9 Estos testimonios guardan coherencia con la creación de nuevos espacios urbanos por una elite de tendencia oligárquica que, desde comienzos del siglo $\mathrm{XX}$, busca separarse y diferenciarse del pueblo. ${ }^{10}$ Leyva Arroyo coincide con Stein al sostener que, siendo el vals criollo manifestación cultural de "las clases más pobres y más 'ignorantes'”, no era considerada "decorosa" sino "música de chusma" y carente de "buen gusto"; sin embargo indica que fue ganando adeptos en algunos individuos de los sectores dominantes, como Alejandro Ayarza, apodado "Karamanduka", a quien correspondió "tal vez el primer intento de asumir el vals criollo por un grupo social distinto a su legítimo creador". ${ }^{11}$

En su mayoría, los autores de los valses no recibían beneficios económicos por su actividad artística ni regis-

7 LLORÉNS, José Antonio. Op. cit., 1983; 1987, p. 260.

8 STEIN, Steve. Op. cit., p. 90.

9 Ibídem.

10 DEL ÁGUILA, Alicia. Callejones y mansiones. Espacios de opinión pública y redes sociales y políticas en la Lima del 900, 1997, pp. 42-43.

11 LEYVA ARROYO, C. A. De vuelta al barrio. Historia de la vida de Felipe Pinglo Alva, 1999, p. 38. 
traban oficialmente sus obras. Durante la época de la Guardia Vieja, la canción se aprendía directamente del propio compositor o se transmitía oralmente entre los familiares y los conocidos del barrio. Casi no había canciones escritas, debido más que al analfabetismo de algunos de los autores (en realidad la mayoría sabía leer y escribir), al celo que ponían sobre sus creaciones que no deseaban que fueran copiadas por cantantes de otros barrios. ${ }^{12}$ Esta aprensión sería compartida inicialmente por Felipe Pinglo, según testimonio de su amigo, el también compositor Víctor Correa. ${ }^{13}$

La situación de los compositores cambió con el acceso de la música criolla a la radio a fines de los años treinta y la grabación de discos que comienza en la misma época. La labor de músicos y poetas entró, entonces, en un proceso de profesionalización.

\section{Los espacios de creación, difusión y consumo}

El principal espacio de difusión de las canciones, como queda dicho, era ini- cialmente el barrio, y concretamente el callejón o la casa de vecindad donde se realizaba la jarana o festividad. La difusión era básicamente oral. En los primeros años del siglo XX, los barrios estaban rodeados de huertas y la mayoría de los limeños vivía en callejones y casas de vecindad, en condiciones muy precarias de hacinamiento y falta de servicios básicos. ${ }^{14}$ Las jaranas tenían lugar especialmente en los cumpleaños o en las fiestas del santo patrono del callejón. Entonces, los vecinos daban una contribución económica voluntaria para comprar cohetes, velas, pisco y papeles de colores para hacer cadenetas. ${ }^{15}$ En ocasiones menos solemnes, la organización de la jarana era más sencilla: una guitarra, un cajón, una banca y una botella de pisco. ${ }^{16}$

Otros espacios de la música criolla fueron "disimuladas casas de citas", como señala Hugo Neira, ${ }^{17}$ basándose en los recuerdos de Eudocio Carrera Vergara. ${ }^{18}$ Neira sugiere que el vínculo de Alejandro Ayarza, "Karamanduka", con la música popular se estableció en esos lugares, además de huertas y cha-

12 SANTA CRUZ GAMARRA, C. El waltz y el valse criollo. Nuevas consideraciones acerca del valse criollo, 1989, p. 79.

13 LEYVA ARROYO, C. A. Op. cit., p. 33.

14 Leyva ARroyo, C. A. Op. cit., p. 13; DEL ÁGUila, A. Op. cit., pp. 30-38.

15 LEYVA ARROYO, C. A. Op. cit., p. 14.

16 STEIN, Steve. Op. cit., p. 90.

17 NEIRA, Hugo. "El vals peruano o la alegría sollozante". Hacia la tercera mitad. Perú XVI-XX, 1996, p. 448.

18 CARRERA VERGARA, E. La Lima criolla de 1900, 1954. 
cras donde también se celebraban jaranas. Ayarza, oficial de la Guardia Republicana, "bohemio y blanco", integraba con otros jóvenes de "buena familia", un grupo de bravucones denominado "La Palizada", ${ }^{19}$ que frecuentaba a truhanes de barrios populares y era empleado eventualmente por los políticos de turno en época de elecciones como fuerza de choque. ${ }^{20}$ Del Águila ${ }^{21}$ prefiere destacar "el perfil de posibles intermediarios" (políticos, sociales y culturales) de los miembros de "La Palizada", que facilitaban una "vinculación interespacial" entre ciertos notables y el pueblo, permitiendo a los primeros "acercarse más a sus clientes populares" y a estos "asegurarse la protección y el contacto con el mundo de los notables, que era también el de los bienes y favores".22

Deben mencionarse que, de otro lado, la canción criolla llegó, a comienzos de los años veinte, a los espacios de los sindicatos y las asociaciones obreras. No debemos olvidar que los autores eran, en su mayoría, artesanos y obreros; y, como han revelado Espino $^{23}$ y Lévano, ${ }^{24}$ en esos espacios los versos de valses y polcas conocidos eran cambiados por otros que expresaban el sentimiento libertario de los trabajadores.

La difusión de partituras de estos artistas populares debió ser muy reducida, pues ha quedado poquísima música escrita de la primera época. Los versos de las canciones, como ya se ha señalado, tampoco contaban al comienzo con difusión escrita, por el temor de los creadores a ser copiados. Cada barrio tenía sus autores y cantantes, sus temas y hasta su propio estilo de interpretación y composición. Sin embargo, ya desde 1900 venía circulando El cancionero de Lima, en el que aparecían transcritas canciones criollas. Este primer medio de difusión contribuyó a romper las fronteras de los barrios, uniéndolos por el mercado, y permitió que en unos casos se iniciara, y en otros se

19 Es muy conocido el vals del mismo nombre compuesto por Ayarza. Sus dos primeras estrofas dicen: "Somos los niños más conocidos / de esta bella y noble ciudad, / somos los niños más engreídos / por nuestra gracia y sagacidad. // De la jarana, somos señores / y hacemos flores con el cajón, / y si se ofrece tirar trompadas, / también tenemos disposición". Ayarza, según Basadre, participó, como jefe de gendarmes, en la represión de las huelgas de los obreros anarcosindicalistas en 1917 (La vida y la obra. Ensayos sobre personas, lugares y problemas, 1981, p. 170).

20 SANTA CRUZ GAMARRA, C. Op. cit., pp. 129-130.

21 DEL ÁGuila, A. Op. cit., p. 108.

22 Ibídem, p. 109.

23 ESPINO, Gonzalo. La lira rebelde proletaria. Estudio y antología de la poesía obrera anarquista 19001926, 1984.

24 LÉVANO, Edmundo. Un cancionero escondido. Historia y música del Centro Musical Obrero de Lima: 1922-1924, 1988. 
consolidara la fama de compositores y cantantes populares. ${ }^{25}$

A partir de los años veinte se encontró en los teatros y cines de barrio nuevos espacios de presentación de canciones. En 1929, Felipe Pinglo estrenó el vals Rosa Luz, interpretado por Alcides Carreño, en el teatro Apolo de Barrios Altos, y, en 1930, El plebeyo, en el teatro Alfonso XIII del Callao. ${ }^{26}$

La acogida de la canción criolla por la radio era aún tímida. En 1935, Pinglo se presentó con el dúo Costa y Monteverde en Radio Internacional para cantar El espejo de mi vida. ${ }^{27}$ Paradójicamente, al poco tiempo de muerto Pinglo (quien falleció en 1936), se dio el gran despegue masivo de la canción criolla, promovido por el gobierno de Benavides, en la radio estatal y en varias de las nuevas emisoras privadas. Se creó así un gran espacio virtual para la canción criolla, y un nuevo espacio físico: el de los auditorios de las emisoras, que comenzaron a construirse a partir de los años cuarenta.

Por entonces, también se fundaron los centros musicales, antecedente de lo que serían más tarde las peñas. Los primeros centros musicales llevaron los nombres de Carlos A. Saco y Felipe Pinglo. Se trataba de espacios nuevos que contaron con el apoyo de medios masivos como los diarios El Comercio y La Prensa, respectivamente, y constituyeron, según Santa Cruz Gamarra, un "intento de criollismo institucionalizado". ${ }^{28}$

Las empresas fonográficas no acogieron la música criolla sino hasta fines de los años treinta, cuando ya había empezado a imponerse en la radio. Una excepción la constituyeron las canciones grabadas por Eduardo Montes y César Manrique en 1911 para la firma norteamericana Columbia Fonograph \& Company (91 discos dobles con 182 piezas). ${ }^{29}$

25 El cancionero de Lima era editado por la Imprenta Ledesma, de propiedad de Mario Ledesma Sotomayor, quien empleaba el seudónimo de "Marqués de Lema" (Lévano, Edmundo. Un cancionero escondido..., 1998, p. 24); Zanutelli (Canción criolla. Memoria de lo nuestro, 1999, p. 22) dice que esta publicación fue fundada en 1910; Leyva Arroyo (De vuelta al barrio..., 1999, p. 33) sostiene que apareció a mediados de la década de 1910; Lévano (op. cit., p. 23) pone como fecha "hacia 1916" y añade que duró medio siglo; sin embargo, en la hemeroteca de la Pontificia Universidad Católica del Perú se encuentran dos números (21 y 23) correspondientes a 1900.

26 Miranda TARrillo, Ricardo. Música criolla del Perú: Breve bistoria, 1989, p. 80.

27 Ibídem.

28 SANTA CRUZ GAMARRA, C. Op. cit., p. 82.

29 Las grabaciones de Montes y Manrique tuvieron gran acogida, a juzgar por lo afirmado en una nota de la revista Variedades (Lima, 20 de mayo de 1914, p. XVIII), según la cual en ocho meses se vendieron veinticinco mil discos. En 1927, la Casa Victor grabó marineras y tonderos, y en 1930 yaravíes y huaynos (ZANUTELLI, M. Op. cit., pp. 105-106). 
El cine peruano de fines de los treinta y comienzos de los cuarenta acogió también a la música criolla, especialmente en las producciones de Amauta Films. Gallo de mi galpón (1938), por ejemplo, incluía canciones de Pinglo y Pedro Espinel, e intérpretes como Jesús Vásquez y Alicia Lizárraga.

\section{Apropiaciones e influencias}

\section{Tradición y valores populares}

En su biografía sobre Felipe Pinglo, Carlos Leyva Arroyo afirma que fue en las fiestas de Barrios Altos donde el compositor "fue conociendo y asumiendo la tradición artístico-musical a la cual pertenecía”. Añade que una de las "características medulares de esa tradición fue su propensión por conocer, recrear y, en algunos casos, asimilar formas literario-musicales foráneas; lo que se constituyó en el vehículo principal para su continuo enriquecimiento". 30

Es interesante cómo Leyva considera que parte de la tradición popular es la asimilación y recreación de bienes provenientes de otras culturas. Para la época de la formación de la canción criolla, ya se asumía como propia una tradición de versificadores populares (copleros y decimistas) que habían asimilado la poesía popular española; también se consideraba propio el ritmo negro (en verdad, heredado del África) que aligeró el tempo del vals vienés y la polca (hay que recordar que muchos compositores criollos eran negros). Propia era, asimismo, la fiesta, pero, sobre todo, ciertos valores populares y vivencias urbanas, no solo las de la pobreza y la marginalidad, sino también las de la modernidad y el cambio.

La designación que hace Stein ${ }^{31}$ de los valores de la clase trabajadora (conformismo, resignación y acatamiento de la autoridad) a partir del análisis de algunos valses, ha sido cuestionada, creemos con razón, por Lévano, ${ }^{32}$ quien para refutarla destaca los valores opuestos contenidos en los cancioneros rebeldes publicados por obreros anarquistas de la época. Pero aun en composiciones de trabajadores con opciones políticas menos definidas se pueden hallar valores muy distintos a los considerados por Stein. Ya en las canciones de la Guardia Vieja se homenajeaba a un bandolero como Luis Pardo, ejemplo de desafío a la autoridad. 33

30 LEYVA ARROYO, C. Op. cit., p. 22.

31 STEIN, S. Op. cit.

32 LÉVANO, E. Op. cit.

33 "Por eso yo quiero al niño / por eso yo amo al anciano; / y al pobre indio que es mi hermano, / le doy todo mi cariño. / No tengo alma de armiño / cuando sé que se les explota: / toda mi cólera brota / 
Es de destacar, además, que ciertos valores populares fueron mutando con los cambios sociales y urbanos producidos alrededor de los años veinte: de una suerte de fatalismo que se aprecia aún en muchas composiciones de la Guardia Vieja, y del temor ante el progreso (expresado en una canción como Los motoristas de Belisario Suárez, que lamentaba la llegada del tranvía por el desempleo que iba a causar entre los conductores), se pasa a la celebración de la modernidad en El volante y Amor a 120 de Pinglo, ${ }^{34} \mathrm{e}$ incluso a la exaltación, sumamente moderna, de la vivencia del instante (La canción del porvenir). ${ }^{35}$ La valoración del deporte (e indirectamente de la salud y la higiene que este representa) es otra novedad de la generación de Pinglo.

Así como es cuestionable el reduccionismo de los valores populares que hace Stein, lo es también la atribución a la canción criolla de una temática exclusiva o mayoritariamente luctuosa, como lo hace Sebastián Salazar Bondy. ${ }^{36}$ Si bien esta temática se encuentra en algunos valses, debe tenerse en cuenta que la interpretación de ellos se realizaba, como hemos dicho, en un contexto específico donde adquiría plena significación; es decir, en el interior de la jarana, donde la música y la coreografía festivas hacían contrapunto con las penas cantadas. No se trataba, entonces, de que se celebrara la muerte, como dice Salazar Bondy, ${ }^{37}$ sino de que se derrotaba a la penas.

De otro lado, no eran cantadas únicamente "penas y tristezas", como rezaba el vals de la Guardia Vieja $L a$ pasionaria. Un rápido recuento de los temas tratados por Felipe Pinglo en sus composiciones permite descubrir que se habla en ellas del niño y la mujer trabajadores (El canillita, Pobre obrerita), el music hall (El cabaret), las drogas (Sueños de opio), los juegos de azar (Casino), la hípica (José Herrera), el automóvil (El volante), la velocidad (Amor a 120), el fútbol (Alejandro Villanueva), y deportes en general como el béisbol, el básquet, el remo y boxeo (Callao for ever). Lo que la generación de Pinglo expresaba en sus canciones, en buena cuenta, era la experiencia

para su opresor, me indigna / como la araña maligna / que sé aplastar con mi bota" (segunda estrofa de El canto de Luis Pardo, según la versión recopilada por Abelardo Gamarra y reproducida por SERRANO, R. y E. VALVERDE. El libro de oro del vals peruano, 2000, p. 22).

34 LLORÉNS, J. A. Op. cit., 1987, p. 275.

35 "Canta y baila, ríe y goza / haz tu fiesta corazón / no pienses en el mañana / porque sentirás dolor / piensa que la vida es corta / y que vives para el hoy".

36 SALAZAR BONDY, Sebastián. Lima la horrible, 1974.

37 Ibídem, p. 130. 
de la modernidad desde los sectores populares, experiencia que podía tener tanto de fascinación ante la velocidad y el cambio, como de melancolía por la vivencia de la fugacidad del tiempo.

\section{Apropiación y resemantización de la cultura de la elite}

El vals criollo tiene su fuente musical más importante en el vals vienés, que llegó a los salones limeños del siglo XIX, y al que los sectores populares impusieron "características específicas" de coreografía, ritmo, melodía, armonía y poesía". ${ }^{38}$ Santa Cruz Gamarra menciona, además, la influencia de la zarzuela, la jota española y la mazurca, y propone la hipótesis de que fueron las estudiantinas y conjuntos menores (dúos, tríos y cuartetos) los verdaderos responsables de la "aclimatación popular del vals vienés". 39

En el campo específicamente literario, las influencias de la poesía romántica y modernista parece eviden- te. Se trataba de poesía rimada que facilitaba el empleo de la memoria y que podía ser asimilada por quienes habían incorporado ya a su tradición coplas y décimas. Así como los poetas populares inventaban versos sobre la base de la música de jotas, mazurcas o resbalosas preexistentes, también se dio el caso de poemas tomados de la vertiente culta a los que compositores populares pusieron música. Tal fue lo que ocurrió con el vals El guardián, uno de los más conocidos de La Guardia Vieja, cuyos versos son del poeta colombiano Julio Flórez y la música del peruano Juan M. Peña, ${ }^{40}$ o con el vals La rosa del pantano, cuyos versos fueron tomados del poema Déjalos del cubano Bonifacio Byrne, y musicalizados por el peruano Fausto Florián. ${ }^{41}$

En la adopción de un vocabulario y una "manera de decir" que se pretende culta, se aprecia, asimismo, un intento de apropiación de los sectores subalternos del lenguaje de los señores. En La oración del labriego, por ejemplo, Pinglo dice: "Es ya de madru-

38 LEYVA ARROYO, C. A. Op. cit., p. 28.

39 SANTA CRUZ GAMARRA, C. Op. cit., pp. 26-28.

40 LÉVANO, E. Op. cit., p. 21; ZANUTELLI, M. Op. cit., p. 91.

41 Las modificaciones realizadas por los cantantes populares a los versos de El guardián han sido objeto de comentario irónico por Luis Loayza ("Vals variable". El sol de Lima, 1974). La célebre primera estrofa de El guardián dice: "Yo te pido, guardián, que cuando muera / borres los rastros de mi humilde fosa / No permitas que nazca enredadera / ni que coloquen funeraria losa”. La estrofa más conocida de La rosa del pantano dice: "Qué importa del mundo / su juicio vano / su pequeñez no alcanza / a nuestro amor, / la rosa que ha nacido en el pantano, / aunque el mundo no quiera, / es una flor". 
gada, el labriego despierta / al entreabrir sus ojos luz del alba ve / entonces presuroso saliendo de su lecho / musita esta plegaria lleno de amor y fe". Con el empleo de términos como "labriego", "presuroso", "musita", "lecho" y "plegaria", Pinglo aspira, aparentemente, a acceder a un lenguaje que considera "superior". En ello, si bien se manifiesta la subordinación a la cultura de elite, también se halla implícita una demanda de reconocimiento: a la igualdad en el habla debía corresponder una igualdad en el trato. Esta suerte de afán de demostración de destreza en el uso del habla culta llega al alarde y la parodia en la polca Palabras esdrújulas, del mismo Pinglo, cuya primera estrofa dice: "Soñando en el hipótesis de aquel país idílico / los organismos psíquicos de espíritu ancestral / resuenan en mis oídos melódicas romanzas / y puedo el fluido etéreo exótico aspirar".

Por cierto, la elite encontró los versos de las canciones criollas anacrónicos y "huachafos", y solo les concedió valor a sus cultores cuando se vio presionada por los movimientos de masas y la crisis de los años treinta.
De otro lado, se percibe en las canciones criollas la influencia de un concepto de lo "criollo" que la elite fue elaborando desde mediados del siglo XIX, a partir de la generación de Ricardo Palma. Este concepto igualaba a lo criollo con lo limeño, y a lo limeño con lo peruano (lo que implicaba obviamente la exclusión de lo andino), y comprendía cierta añoranza por la época virreinal. Sin embargo, aunque existen canciones, tanto de la Guardia Vieja como de la generación de Pinglo, en las que se halla el tema de la añoranza, estas son menos de las que se cree, y la nostalgia es más republicana que virreinal. ${ }^{42}$ Como señala Lloréns, la Guardia Vieja no cantó al pasado porque lo estaba viviendo, y la generación de Pinglo cantó más a su presente (en esto coincide hasta Salazar Bondy) y a los cambios que experimentaba con la modernidad. La añoranza no era tanto la de la Colonia como la del barrio al que se retornaba después de unos años. ${ }^{43}$

La etapa nostálgica de la Lima de ayer se iniciará, en realidad, mucho más tarde, en los años cincuenta, cuando, según Lloréns, "los sectores medios y urbanos de la clase dominante de la

42 NEIRA, Hugo. Op. cit., p. 446.

43 Como se puede apreciar en otro conocido vals de Pinglo: "De nuevo al retornar al barrio que dejé, / la Guardia Vieja son los muchachos de ayer / no existe ya el café ni el criollo restaurant, / ni el italiano está donde era su vender. / Ha muerto doña Cruz que juntito al solar solía poner / a realizar su venta al atardecer, de picantes y té. / Ya no hay los picarones de la buena Isabel / todo, todo se ha ido los años al correr" (primera estrofa de De vuelta al barrio de Felipe Pinglo). 
sociedad peruana" tienden "a buscar su propia versión de criollismo frente a la invasión andina”. ${ }^{44}$ Ahora bien, si hubo una corriente tributaria del pasado en los primeros años de la canción criolla, esta fue probablemente la representada por Rosa Ayarza de Morales (hermana de Alejandro Ayarza), formada en la música clásica, recopiladora de pregones y canciones, compositora de marineras y productora de espectáculos teatrales que rememoraban el costumbrismo del siglo XIX.

\section{El papel de los medios masivos}

La difusión a través de la prensa de canciones criollas se realizó desde 1900, en el ya mencionado El cancionero de Lima. A partir de 1938, y a consecuencia del auge de la canción criolla en la radio, aparecieron otras revistascancioneros importantes: Voces en Ondas y Alta Voz. Estas revistas ayudaron a difundir las canciones más allá del espacio de los barrios, y a fijar los versos, muy variables por la tradición oral. No obstante, en ellas se aprecia una distinción entre lo que consideran arte culto y folclore, ubicando dentro de este último a la canción criolla. También asumen la valoración de la elite sobre los versos de las canciones, al considerarlos literariamente pobres. ${ }^{45}$ Las revistas promueven concursos tanto de compositores como de intérpretes, y coronan a reyes y reinas de la canción criolla. Mediante los primeros van orientando el tipo de poesía que consideran "correcta" para la música criolla; a través de la coronación de cantantes contribuyen a la creación de ídolos masivos de origen popular, que puedan constituirse en modelos de conducta para los sectores subalternos.

Otro tipo de publicación de masas que pudo tener singular influencia en la canción criolla fue el Almanaque Bristol. Según testimonios de compositores de la Generación de Pinglo, los poemas aparecidos en ese medio eran a veces musicalizados por los artistas populares. Se trataba de poemas "pasados de moda”, de autores generalmente románticos. Serrano y Valverde especulan que los versos de El guardián fueron leídos por Juan M. Peña en el Almanaque Bristol antes de que este cajoneador chalaco les pusiera música. ${ }^{46}$

Los discos, cuya venta se intensificó en el país en los años veinte, extendieron el gusto entre los sectores populares del foxtrot, el one step y el tango, y generaron, como se ha dicho, una crisis de la música criolla a comienzos de esa década. Sin embargo, los ritmos

\footnotetext{
44 LLORÉNS, J. A. Op. cit., 1983, p. 76.

45 "Editorial". Alta Voz 2.

46 SERRANO, R. y E. VALVERDE. Op. cit., p. 26.
} 
norteamericanos fueron acogidos por los jóvenes compositores de la generación de Pinglo, que escribieron canciones sobre la base de ellos. A partir de 1938 se comenzaron a grabar discos con canciones criollas de modo regular, lo que amplió el consumo pero también impuso restricciones: la duración de las canciones se redujo a la duración estándar del soporte.

El cine también ejerció influencia. A partir de 1930 las películas sonoras se hicieron frecuentes en el Perú; muchas de ellas eran musicales. Santa Cruz Gamarra recuerda: "A más películas musicales, más música de jazz que consumir". 47 Destaca, asimismo, que la música de El sueño que yo viví, de Pinglo, fue tomada de la canción Sunny Side Up de B. G. de Sylva, Lew Brown y Ray Henderson, compuesta para la película del mismo nombre. ${ }^{48}$ Felipe Pinglo, quien según César Santa Cruz Gamarra "fue siempre simpatizante del jazz", 49 escribió varias letras de fox trots que se interpretaron más tarde como one steps y luego como polcas criollas.
La música norteamericana que venía en discos y filmes, si bien se hallaba filtrada por estos medios de masas, tenía un origen popular, y puede clasificarse dentro del amplio espectro del jazz. Lévano resalta el "certero instinto" de los artistas populares peruanos al ver en ella "música de negros y, por lo tanto, de hermanos".50 Algo similar ocurría con el tango, cuyo origen popular generó un reconocimiento de los llamados sectores subalternos de los motivos de sus letras: barrios pobres, calles mal alumbradas y peligros urbanos que acechaban a las personas de pocos recursos económicos. Lévano añade énfasis en los componentes de cultura negra que habría en el tango. ${ }^{51}$

La influencia de la radio sería menor en los primeros años del funcionamiento de este medio, y sumamente importante al final de los años treinta. La primera estación de radiodifusión se inauguró en el Perú en 1925; se llamó O.A.X. y fue propiedad de un consorcio privado que quebró el año siguiente, pasando la emisora a poder del Estado. ${ }^{52}$ Durante nueve años fue

47 SANTA CRUZ GAMARRA, C. Op. cit., p. 74.

48 El sueño que yo viví fue, además, el título en castellano con el que se estrenó Sunny Side Up (1929) en Lima. El filme fue dirigido por David Butler, y actuaban Janet Gaynor y Charles Farell. Su estreno en nuestra capital tuvo lugar el 19 de febrero de 1931 en el cine Excelsior (NÚÑEZ GORRITI, Violeta. Cartelera cinematográfica peruana 1930-1939, 1998, p. 33).

49 SANTA CRUZ GAMARRA, C. Op. cit., p. 180.

50 LÉVANO, E. Op. cit., p. 24.

51 Ibídem, p. 25.

52 ALEgría, Alonso. O.A.X. Crónica de la radio en el Perú (1925-1990), 2003; GARGUREVICH, Juan. La Peruvian Broadcasting Co. Historia de la radio I, 1995. 
la única estación existente en el país; en 1937 se convirtió en Radio Nacional del Perú. En los primeros tiempos su audiencia era muy reducida debido al alto costo de los receptores y a que debía pagarse una suscripción para escucharla. Su programación, por tanto, estaba dirigida a un público de elite al que, sin embargo, tampoco lograba cautivar. La situación de la radio va a cambiar luego de superada la crisis económica y política de comienzos de los años treinta. Las primeras emisoras privadas empiezan a surgir a partir de 1934, y emiten música variada. Para entonces la tecnología ha mejorado, se elaboran receptores más baratos que son vendidos a plazos. La audiencia del medio se hace masiva y popular, y al poco tiempo acoge a la música criolla. Ello, no obstante, tiene efectos sobre la producción de las canciones. Los autores e intérpretes se empiezan a profesionalizar, la obra musical comienza a ser editada en partituras, y las canciones se reducen en tiempo y estrofas:

Ya nadie compone valses de tres o cuatro partes; son difíciles para los nuevos intérpretes, pues ellos prefieren obras que se memoricen en corto tiempo, que sean de rápida aceptación por el público oyente y que no ofrezcan mayores complicaciones para su montaje (ensa- yo). Los valses quedan definitivamente reducidos a dos partes o temas. ${ }^{53}$

La radio acabó definitivamente con la exclusividad del repertorio y el estilo de los barrios, pero dio a la canción criolla una difusión muy amplia, creando, como hemos dicho líneas arriba, un gran espacio virtual para su consumo y contribuyendo, de manera fundamental, a otorgarle un carácter "nacional". Como hemos señalado también, la radio aportó un nuevo espacio físico de consumo de las canciones, distinto al barrio, el callejón o el teatro: el auditorio de la emisora. Algunos de los cantantes y compositores, además, con la complicidad de la prensa, obtuvieron un rango de "estrellas", es decir, alcanzaron una condición mítica, convirtiéndose en arquetipos y ejemplo de ascenso social para los sectores populares.

\section{Los usos}

\section{Los usos populares}

Los usos populares de la canción criolla han sido más o menos expuestos hasta aquí. Como ya se ha señalado, la canción criolla fue empleada por los sectores populares para expresar múltiples vivencias y afirmar valores. Sirvió para la celebración y la fiesta,

53 SANTA CRUZ GAMARRA, C. Op. cit., p. 79. 
para recordar a los héroes populares (desde Luis Pardo hasta los futbolistas de Alianza Lima), para lamentos y cortejos sentimentales, para dar cuenta de los cambios operados en la vida cotidiana del pueblo a causa de la modernidad, y de cómo eran sentidos por sus integrantes. También para la manifestación de la protesta y del sentimiento libertario. Nos interesa más indicar ahora, cómo el Estado y los sectores hegemónicos, tras ignorar a la canción criolla, recurrieron a ella para emplearla como mediadora en un momento de crisis, convirtiéndola en manifestación cultural de la "nacionalidad", pero sin otorgar a su poesía estatus literario.

\section{Los usos del Estado}

Desde comienzos del siglo XX hubo valses escritos en homenaje a personajes públicos que ocupaban el poder o se hallaban muy cerca de él. Zanutelli cita uno dedicado al presidente Pardo y otro al hijo del presidente Leguía. ${ }^{54}$ En ellos se pueden vis- lumbrar las redes de favores y padrinazgos que vinculaban verticalmente a los pobladores de Lima y caracterizaban al "negocio político" en las primeras décadas del siglo XX. ${ }^{55}$

No obstante, existía una población obrera con mayor conciencia política que participó activamente en las luchas que culminaron con la obtención de la jornada de las ocho horas en 1919. Asimismo, desde fines del siglo XIX se venía incrementando la población popular urbana, y ello se hacía sentir en los espacios públicos, fueran estos dedicados al espectáculo, al deporte o a la manifestación política. Se asistía a la generación de una verdadera masa urbana. Hacia 1912 había quedado en evidencia que el viejo civilismo no era capaz de asumir la representación de esta masa, que fue la que prácticamente decidió la elección de Billinghurst en contra del candidato civilista Aspíllaga. Como sabemos, Billinghurst no duró en el poder porque el ejército, al mando de Benavides y al servicio de la oligarquía, lo derrocó.

54 El dedicado a Pardo es de Alberto Aguilar con música del vals Francia: "Llegó el Perú por fin a ver / que rige sus destinos hoy, / el hombre que ha llegado a ser / de la patria el protector / por su gran labor". El dedicado a Juan Leguía es de José María Barrientos y apareció en el número 349 de El Cancionero de Lima: “¡Oh! intrépido aviador, tú el mimado del Perú, / quien valiente sino tú, / que a la muerte no le temes, en los aires te entretienes / demostrando gran valor. // Mi pecho canta con gloria / que viva don Juan Leguía / que a la patria consoló / cuando un hijo perdió / en este funesto día / y a él en los aires se vio. // Viva el Perú, patria amada, / y viva don Juan Leguía, / que viva la valentía / que el intrépido aviador / vuela con gloria y honor / en este solemne día" (ZANUTELLI, Manuel. Op. cit., pp. 52-53).

55 DEL ÁGUILA, A. Op. cit., pp. 166-167. 
En los años veinte, las medidas populistas de Leguía no impidieron la caída de su gobierno, a consecuencia, fundamentalmente, de la crisis generada por el crack de 1929. La representatividad de la masa popular urbana, sobre la que recaía la parte más dura de la crisis, fue asumida entonces por nuevos actores políticos, en particular por el Apra y el Partido Comunista, liderados por jóvenes, en su mayoría de clase media, formación universitaria y origen provinciano; pero también por una agrupación de corte fascista como la Unión Revolucionaria, que tenía como líder al comandante Sánchez Cerro.

Los mítines políticos previos a las elecciones de 1931, que ganó la Unión Revolucionaria, la insurrección aprista y la guerra civil de 1932 pusieron en evidencia un cambio radical en el panorama político del país, donde los sectores populares urbanos ocupaban un lugar decisivo. El asesinato del presidente Sánchez Cerro y la asunción del mando, nuevamente, por el general Benavides trajeron consigo una fuerte represión contra los dirigentes de los partidos de izquierda, pero ella no resolvía por sí misma el problema de la falta de representatividad del Estado respecto de un amplio sector social cuyas demandas no eran satisfechas.
Favorecida por la superación de la crisis económica gracias al incremento de los precios del algodón, la dictadura de Benavides llevó a cabo una serie de medidas orientadas a satisfacer demandas de los sectores populares. Se creó así el Hospital Obrero, el Seguro Social, el Ministerio de Salud y el Ministerio de Educación. Se inició, al mismo tiempo, una prédica nacionalista con la que se buscó integrar a la población por encima de las diferencias sociales y económicas; ese discurso llevaba un subtexto de rechazo a propuestas políticas que se consideraban "foráneas", como las del aprismo y el comunismo. Luego de las elecciones de 1936, que fueron anuladas una vez que triunfara en ellas Luis Antonio Eguiguren, candidato respaldado por el Apra, el gobierno de Benavides emprendió una política de comunicación acorde con su discurso nacionalista, orientada más al interior del país que al exterior, y en la que tenía explícitamente un papel protagónico la radio. ${ }^{56}$ En 1937, la emisora OAX se convierte en Radio Nacional del Perú, y el cambio de nombre va acompañado de una muda de local, la adquisición de modernos y potentes equipos, y una programación que tiene como destinatarios a los sectores populares.

La música criolla adquiere singular importancia en la emisora del Estado

56 PERLA ANAYA, José. La radiotelevisión. Espectro del poder y del futuro, 1995, p. 50. 
precisamente a partir de aquel año. Se convierte en la música "nacional", siendo su presencia en el dial superior al de la música andina, de la que se toman solo las variantes más estilizadas (como las interpretadas por Ima Súmac y Moisés Vivanco), no las más populares, que recién tendrán acceso al medio masivo en los años cincuenta, cuando cambió el rostro de Lima con las nuevas olas migratorias. Despreciada durante décadas por la elite e ignorada por los poderes públicos, la canción criolla, expresión cultural y artística de los trabajadores urbanos limeños, adquiere así un reconocimiento del Estado, debido a la necesidad de este de asumir la representatividad de esos sectores que peligrosamente se estaban desbordando y reconociendo dirigencias que cuestionaban su autoridad.

El reconocimiento de la música criolla por el Estado como "nacional" implicaba, no obstante, atenuar las diferencias sociales bajo una supuesta única "tradición", así como la orientación de comportamientos de los sectores populares de acuerdo con normas cívicas y valores de quienes detentaban el poder. Tal como eran satisfechas las explícitas demandas económicas y sociales, lo eran también las implícitas demandas culturales. Se les otorgaba derechos a los trabajadores, pero bajo las condiciones de acatamiento de las normas impuestas por el Estado. De modo similar a como en el campo de lo político y social quedaba seriamente limitada la organización autónoma de los trabajadores, los temas y versos de las canciones debían en adelante adecuarse a las expectativas del Estado y de los sectores que se pretendían hegemónicos.

No ha podido ser demostrada la supuesta censura a versos de canciones criollas durante el régimen de Benavides, pero sí puede hallarse, en el número 2 de la revista-cancionero Voces en Ondas (destinada a un público popular), una marcha para piano con versos de autor desconocido y música de J. Z. Purizaga, que es de obvia propaganda al régimen. La letra dice:

En cuatro años y meses de gobierno / laborioso, patriota y paternal / consolida el Perú su orden interno / y conquista prestigio universal. // Los empleados y obreros carecían / de asistencia social y atención / y el triste desamparo en que vivían / ha cesado al brindarles protección / Vías libres, / barrio obrero, / dique seco, / previsión, / más escuelas / y al deporte / la mayor dedicación. // El Ejército, la Armada y la Aviación nacional / provistos en abundancia / de moderno material. // Auxilio a los hospitales / desayuno a los niños / jubilación, cesantía / y asistencia en la vejez. // Aumento de los ingresos / de la Hacienda Nacional / y los pagos con el día / con agrado general. // Auxilio a las madres pobres, / control a la inmigración, Universidad abierta / y aumento en la exportación // Vías libres... 
La institucionalización de la canción criolla por parte del Estado tuvo su punto culminante en 1944, bajo el primer gobierno de Manuel Prado, cuando por ley se creó un día del año dedicado a ella.

\section{Los usos de la elite}

Ya ha sido mencionado el desprecio que suscitaba la música criolla en los sectores hegemónicos durante los primeros años del siglo XX. ${ }^{57}$ La elite consideraba la música criolla una manifestación de sectores "bajos"; disfrutarla implicaba, en cierto modo, descender socialmente. Los miembros de las clases acomodadas que participaban en jaranas criollas, como Alejandro Ayarza, "Karamanduka", a despecho de su función de intermediarios subrayada por Del Águila ${ }^{58}$ o de que cumplieran un rol de padrinos, no eran bien vistos por su clase social. Jorge Basadre recuerda que las "personas finas" que acudían al Teatro Victoria para ver las zarzuelas estrenadas por "Karamanduka” entre 1910 y 1912 lo hacían con una actitud vergonzante. 59

Si la canción criolla era considerada algo "bajo" por la elite, su conver- sión en signo de nacionalidad hacia fines de los años treinta demandaba que fuera "elevada" por ella. Los primeros intentos por "elevar" la música criolla correspondieron a la hermana de Alejandro Ayarza, Rosa Ayarza de Morales, quien además de maestra de canto lírico era, como hemos señalado, recopiladora de pregones y canciones antiguas. El 28 de julio de 1938, bajo el gobierno de Benavides e impulsada ya la política "nacionalista” del régimen, se realizó en el Teatro Municipal un recital de música criolla con asistencia del presidente y el auspicio del Concejo de Lima. Las entradas eran caras, pues el espectáculo no estaba destinado a los sectores populares sino a los pudientes. ${ }^{60}$ Según Rosa Ayarza se buscaba que "el público limeño" escuchara las canciones recopiladas por ella para despertar su interés y contribuir a "desterrar la funesta creencia de que nuestros bellísimos aires criollos son algo pecaminoso y subalterno, reñido con la idea de selección artística y social". Añadía: "La presentación del recital en la función de gala será una objetiva lección en ese sentido, demostrando que contamos ya con elementos propios dignos de figurar en un programa de música seria". ${ }^{61}$

57 STEIN, S. Op. cit.; LEYVA ARROYO, C. A. Op. cit.

58 DEL ÁGuila, A. Op. cit.

59 BASADRE, Jorge. Op. cit., p. 170.

60 ZANUTELLI, M. Op. cit., p. 102.

61 Ibídem. 
Ayarza destacaba también la dificultad del estudio, selección y arreglos de las canciones de origen popular:

... el aspecto realmente complicado y que ha demandado el más paciente estudio y dedicación, ha consistido en la dificultad de expresar, dentro de formas musicales correctas toda la arbitraria y hasta anárquica libertad de los giros musicales populares, sin perder por ello su savia original. Y no se diga nada de las letrillas, de innegable travesura y picante intención, pero frecuentemente imposibles de estampar en una colección destinada a conquistar los estratos superiores de la cultura; allí, ha sido preciso encontrar el sinónimo que exprese la idea con igual donaire y sin ofensa al buen decir [las cursivas son nuestras]. ${ }^{62}$

Para que los sectores altos acogieran la música popular como seria, era pues necesario modificarla y cambiar las letras de las canciones. Sin embargo, es de destacar que para Ayarza la aceptación de la música popular, bajo estas formas estilizadas, era de interés nacional. Se trataba de encontrar (o crear) una manifestación cultural que uniera e identificara a los diferentes sectores, que fuera mediadora entre las clases, y facilitara el orden y la armonía social. Los objetivos de Ayarza y del sector que representaba no se hallaban alejados de la prédica nacionalista del gobierno. La misma Ayarza decía respecto de su espectáculo del 28 de julio de 1938 :

... la concurrencia de altos funcionarios del Estado les permitirá también apreciar la calidad de nuestro folklore musical y sus innumerables proyecciones en lo que se refiere al momento de nuestro sentimiento nacionalista por la exaltación de los valores propios, postergados hasta ahora por importaciones extranjeras, de inferior calidad. ${ }^{63}$

Hay que indicar, no obstante, que la postura de Ayarza respecto de la música criolla no era la única dentro del sector social al que pertenecía. Zanutelli cita al crítico musical Carlos Raygada, quien lamentaba que se hubiera dicho "despectivamente y en son de censura" que el concierto de fiestas patrias de 1938 había incluido "música de negros" (p. 103).

\section{El valor en el mercado}

Superada la crisis de los treinta, eliminado el sistema de suscripción y abaratados los aparatos receptores (que empezaron a venderse a plazos), los sectores populares urbanos se convirtieron en consumidores del medio 
radial. Por su cantidad, los oyentes de estos sectores eran más importantes, para quienes hacían publicidad por radio, que los de la elite. Los programas se dirigían, por tanto, a un público popular. La creciente presencia de la canción criolla fue objetada por algunos voceros de la elite que reclamaron "elevar el nivel cultural" del medio, pero frente a estas protestas los directivos de las emisoras tenían una posición muy clara. El director artístico de Radio Lima, Roberto Cruzalegui, declaraba en noviembre de 1938 a la revista Voces en Ondas lo siguiente:

La radiotelefonía, como elemento de recreo, debe estar orientada por el mismo público, y si aquí gusta Tú ya no soplas y Bom-Bom Coronado, pues hay que brindárselos al público hasta que él mismo se harte. Afirmar lo contrario es no conocer de radiotelefonía. Ahora que debe ser un vehículo de cultura, estamos de acuerdo también. Pero todo tiene su medida. Y para ello existen métodos que están supeditados al ambiente en general. Si siguiendo el método de Berlín, Londres o Ámsterdam, Radio Lima pusiese todas las noches en sus programas a una orquesta para que toque a Wagner, Bach, Borodin, Debussy, Falla, etc., entonces la gran masa se iría a escuchar otras estaciones. Y al suceder esto, nuestros anunciantes, que son el único sostén que tenemos (porque Radio Lima no se ha hecho para entretenimiento de sus dueños ni de sus directores), se irían con sus programas y avisos a otras estaciones de menor importancia que no hubiesen seguido el depuradísimo ejemplo, y al fin y al cabo clausuraríamos la estación. ${ }^{64}$

Las declaraciones de Cruzalegui dejan en claro que los intereses del mercado favorecían en la coyuntura la emisión de música criolla, pero también los objetivos del gobierno, aunque para este se tratase de educar a las masas, contenerlas y obtener representatividad, y para los dueños de las emisoras de entretenerlas y conseguir dinero. Los propietarios y directivos de las estaciones privadas no tenían, sin embargo, en alta estima la cultura de sus oyentes (que era la misma que se expresaba en las canciones que irradiaban) ni pretendían "elevarla". El mismo Cruzalegui definía el "carácter" de la radio que dirigía:

Frivolidad, ligereza, ausencia de literaturas que no hacen sino fatigar al oyente poco versado. Porque, usted sabe amigo mío, en el Perú abundan los inteligentes, pero no abundan los buenos entendedores. Si yo para decir, por ejemplo, que determinado elemento vocal o instrumental tiene un agradable sonido, digo que es eufónico, posiblemente me he ganado un admirador versado, pero en cambio ha habido diez

64 Voces en Ondas 41, p. 5. 
mil que no me han entendido. Ahora calcule Ud. cuántos oyentes perdería Radio Lima si esto se repitiese en nuestras audiciones día tras día, hora tras hora... ${ }^{65}$

A consecuencia del éxito de los cantantes criollos en la radio, se empezaron a grabar discos de manera regular a partir de 1938, aunque a decir de una nota aparecida el 30 de agosto de 1938 en el número 32 de Voces en Ondas (p. 24), la calidad de estas grabaciones era deficiente.

Revistas "populares" como Voces en Ondas, dedicadas a informar sobre la programación de las emisoras y la farándula radial, surgieron a partir de 1937. Tenían varias páginas de cancionero. Algunas de estas publicaciones eran muy proclives al gobierno y a su política "nacionalista". Ya hemos citado la canción dedicada al presidente Benavides, aparecida en el número 2 de Voces en Ondas. En ese mismo número, el editorial de la revista demandaba a las emisoras radiales programar más "música popular" y menos "música clásica", porque "el pueblo busca distracción y no cultura en la radio". Si bien la consideración de la música popular como mero entretenimiento coincidía con la de los dueños de las emisoras, y no necesariamente con la del gobierno, en cualquier caso, su demanda de mayor difusión favorecía a los objetivos del régimen.

Otra de estas publicaciones, Alta Voz ("El cancionero popular peruano. Revista de radio, cine y deportes, dirigido por Juan Malmborg y Guillermo Lecca Iturbe"), tenía una concepción diferente sobre la música popular a la expresada por Voces en Ondas. En su editorial del 14 de junio de 1939, titulado "Dignifiquemos nuestra Literatura Musical", convocaba a un concurso de poesía para ser cantada con los siguientes argumentos:

Los valses y composiciones peruanas tienen música inefable y que llega al sentimiento popular: mas no ocurre lo mismo con la letra. En otros países donde la cultura musical y literaria está más desarrollada, hay escritores y poetas profesionales que se dedican exclusivamente, en acción conjunta con los compositores, a crear letras de tangos y valses nacionales. De allí que resulta una acción armónica entre la melodía y la versificación. Aquí no podremos conseguir otro tanto, pero sí convendría suprimir conceptos y construcciones perversas que deforman la idea musical y reducen la letra a chabacanas expresiones de un barbarismo inexcusable. No se puede negar que contamos con escritores y poetas capaces de llevar a cabo un movimiento a favor de la literatura musical de nuestras canciones.

65 Voces en Ondas 42, p. 6. 
ALTA VOZ, cumpliendo uno de los postulados de su misión periodística, lanza la idea y la hace efectiva, instaurando un concurso de letras para valses, polkas [sic] o canciones nacionales cuyas bases se publicarán en el próximo número. ${ }^{66}$

Del fragmento se desprende: 1. Desprecio por letras populares: "chabacanas expresiones de un barbarismo inexcusable"; 2. Demanda de una "dignificación" de la literatura de las canciones, incorporando a ella a poetas cultos (es decir, formados en la cultura de elite); 3. Deseo de una profesionalización de los músicos y los poetas. Si Voces en Ondas se hallaba más cerca de los propietarios de las emisoras en sus consideraciones de la música popular, Alta Voz parecía ser más afín a un sector de la elite que pretendía "elevar el nivel" de la canción criolla. En cualquier caso, ambas publicaciones debían su existencia al auge de la canción criolla en la radio, y contribuían a su reproducción cultural de manera distinta a como ella había tenido lugar en las dos primeras décadas del siglo.

\section{Conclusión}

La canción criolla fue un producto cultural de los sectores populares urbanos de Lima. En ella se fusionaron, adapta- dos y resemantizados, música y poesía de la elite con aportes culturales propios del pueblo y de la cultura de masas. Fue expresión de múltiples vivencias de los llamados grupos subalternos, entre ellas la experiencia de la modernidad.

Ignorada durante mucho tiempo por los poderes públicos, a raíz de la crisis política de los años treinta, la canción criolla fue usada por el gobierno de Benavides como mediadora entre sectores sociales en conflicto y en función de una política "nacionalista" y de búsqueda de representatividad de una masa popular que parecía desbordar al Estado y optar políticamente por dirigencias distintas a la tradicional.

Despreciada inicialmente por la elite, también a consecuencia de la crisis de los treinta la canción criolla fue asumida por un sector de ella como representativa de la nación (entendida esta como prioritariamente costeña y limeña), pero sometida, a la vez, a un proceso de "depuración" y "elevación" que la hiciera "digna” del papel que se le otorgaba.

Restringida inicialmente a los espacios privados de la jarana, la canción criolla fue acogida por los medios masivos a finales de los treinta, tanto los estatales como los privados, obteniendo una amplia difusión. Este acce- 
so a los medios significó también la profesionalización de autores y cantantes.

No obstante la obtención del reconocimiento del Estado, la elite y los medios, y la extensión de su difusión y audiencia, la canción criolla también sufrió pérdidas en este proceso, tales como la estandarización de su música y la reducción de sus temas y estrofas de acuerdo con las exigencias e intereses de instituciones y sectores diferentes de los que le dieron origen.

\section{Bibliografía}

AlEgría, Alonso. O.A.X. Crónica de la radio en el Perú (1925-1980). Lima: Radioprogramas del Perú, 1993.

BASADRE, Jorge. La vida y la historia. Ensayos sobre personas, lugares $y$ problemas. 2. ${ }^{\mathrm{a}}$ edición. Lima: Industrial Gráfica, 1981.

CARRERA VERGARA, Eudoxio. La Lima criolla de 1900. Lima, 1954.

CORNEJO POLAR, Antonio. La formación de la tradición literaria en el Perú. Lima: CEP, 1989.

DEL ÁGUILA, Alicia. Callejones y mansiones. Espacios de opinión pública y redes sociales y politicas en la Lima del 900. Lima: PUCP, 1997.
ESPINO RELUCÉ, Gonzalo. La lira rebelde proletaria. Estudio y antología de la poesía obrera anarquista (1900-1926). Lima: Tarea, 1984.

GARGUREVICH, Juan. La Peruvian Broadcasting Co. Historia de la Radio I. Lima: La Voz, 1995.

LEYVA ARROYO, Carlos Alberto. De vuelta al barrio. Historia de la vida de Felipe Pinglo Alva. Lima: Biblioteca Nacional del Perú/Pontificia Universidad Católica del Perú, 1999.

LÉVANO LA ROSA, Edmundo. Un cancionero escondido. Historia $y$ música del Centro Musical Obrero de Lima: 1922-1924. Lima: Biblioteca Nacional del Perú/ Pontificia Universidad Católica del Perú, 1988.

LLORÉNS, José Antonio. "De la Guardia Vieja a la generación de Pinglo: Música criolla y cambio social en Lima, 1900-1940", en STEIN, Steve (comp.). Lima obrera 1900-1930. Tomo II. Lima: El Virrey, 1987.

- Música popular en Lima: Criollos $y$ andinos. Lima: Instituto de Estudios Peruanos/Instituto Indigenista Interamericano, 1983.

LOAYZA, Luis. "Vals variable". El sol de Lima. Lima: Mosca Azul, 1974.

MIRANDA TARRILLO, Ricardo. Música criolla del Perú. Breve historia. 
Lima: Ministerio de Educación, 1989.

NEIRA, Hugo. "El vals peruano o la alegría sollozante". Hacia la tercera mitad. Perú XVI-XX. Ensayos de relectura herética. Lima: Sidea, 1996.

NÚÑEZ GORRITI, Violeta. Cartelera cinematográfica peruana 19301939. Lima: Universidad de Lima, 1998.

PERLA ANAYA, José. La radiotelevisión. Espectro del poder y del futuro. Lima: Universidad de Lima, 1995.

SALAZAR BONDY, Sebastián. Lima la borrible (1964). Lima: Peisa, 1974.

SANTA CRUZ GAMARRA, César. El waltz y el valse criollo. Nuevas consideraciones acerca del valse criollo. Lima: Concytec, 1989.

SERRANO, Raúl y Eleazar VALVERDE. El libro de oro del vals peruano. Lima: Tans Perú, 2000.

STEIN, Steve. "El vals criollo en los valores de la clase trabajadora en la Lima de comienzos del siglo XX". Lima obrera 1900-1930. Tomo I. Lima: El Virrey, 1986.

VILLANUEVA, Lorenzo y Jorge DONAYRE B. Canción criolla. Antología de la música peruana. Tomo I. Lima: Latina, 1987.

ZANUTELLI ROSAS, Manuel. Canción criolla. Memoria de lo nuestro. Lima: Diario El Sol, 1999.

Revistas: El Cancionero de Lima, Voces en Ondas, Alta Voz. 